NASA/TM-2000-210021

ASME 2000-GT-0209

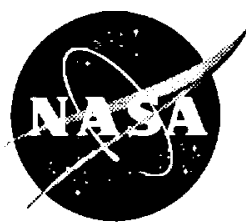

\title{
Heat Transfer Measurements and Predictions on a Power Generation Gas Turbine Blade
}

Paul W. Giel

Dynacs Engineering Company, Inc., Cleveland, Ohio

Ronald S. Bunker

General Electric Corporation, Schenectady, New York

G. James Van Fossen and Robert J. Boyle

Glenn Research Center, Cleveland, Ohio 
Since its founding, NASA has been dedicated to the advancement of aeronautics and space science. The NASA Scientific and Technical Information (STI) Program Office plays a key part in helping NASA maintain this important role.

The NASA STI Program Office is operated by Langley Research Center, the Lead Center for NASA's scientific and technical information. The NASA STI Program Office provides access to the NASA STI Database, the largest collection of aeronautical and space science STI in the world. The Program Office is also NASA's institutional mechanism for disseminating the results of its research and development activities. These results are published by NASA in the NASA STI Report Series, which includes the following report types:

- TECHNICAL PUBLICATION. Reports of completed research or a major significant phase of research that present the results of NASA programs and include extensive data or theoretical analysis. Includes compilations of significant scientific and technical data and information deemed to be of continuing reference value. NASA's counterpart of peerreviewed formal professional papers but has less stringent limitations on manuscript length and extent of graphic presentations.

- TECHNICAL MEMORANDUM. Scientific and technical findings that are preliminary or of specialized interest, e.g., quick release reports, working papers, and bibliographies that contain minimal annotation. Does not contain extensive analysis.

- CONTRACTOR REPORT. Scientific and technical findings by NASA-sponsored contractors and grantees.
- CONFERENCE PUBLICATION. Collected papers from scientific and technical conferences, symposia, seminars, or other meetings sponsored or cosponsored by NASA.

- SPECIAL PUBLICATION. Scientific, technical, or historical information from NASA programs, projects, and missions, often concerned with subjects having substantial public interest.

- TECHNICAL TRANSLATION. Englishlanguage translations of foreign scientific and technical material pertinent to NASA's mission.

Specialized services that complement the STI Program Office's diverse offerings include creating custom thesauri, building customized data bases, organizing and publishing research results ... even providing videos.

For more information about the NASA STI Program Office, see the following:

- Access the NASA STI Program Home Page at http://www.sti.nasa.gov

- E-mail your question via the Internet to help@sti.nasa.gov

- Fax your question to the NASA Access Help Desk at (301) 621-0134

- Telephone the NASA Access Help Desk at (301) 621-0390

- Write to:

NASA Access Help Desk

NASA Center for AeroSpace Information 7121 Standard Drive Hanover, MD 21076 


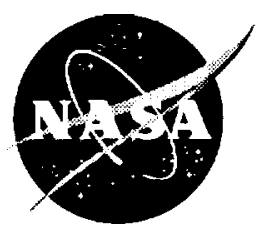

\section{Heat Transfer Measurements and Predictions on a Power Generation Gas Turbine Blade}

\section{Paul W. Giel}

Dynacs Engineering Company, Inc., Cleveland, Ohio

Ronald S. Bunker

General Electric Corporation, Schenectady, New York

G. James Van Fossen and Robert J. Boyle

Glenn Research Center, Cleveland, Ohio

Prepared for the

45th International Gas Turbine and Aeroengine Technical Congress cosponsored by the American Society of Mechanical Engineers and the International Gas Turbine Institute Munich, Germany, May 8-11, 2000

National Aeronautics and Space Administration

Glenn Research Center 


\section{Acknowledgments}

This work was conducted under Space Act Agreement FA-147 between NASA and the General Electric Corporation. It was supported by the NASA Glenn Research Center under contract NAS3-98008 with Dynacs Engineering Co., Inc., • with Mr. Robert J. Boyle as monitor. The work was sponsored by the Turbomachinery and Combustion Technology

Project, as part of the Aerospace Propulsion and Power Research and Technology Program. The support of Ms. Maryann Johnston in digitizing the data and of Ms. Margaret Proctor in measuring the surface roughness is also gratefully acknowledged.

Available from

NASA Center for Aerospace Information 7121 Standard Drive

Hanover, MD 21076

Price Code: A03
National Technical Information Service 5285 Port Royal Road Springfield, VA 22100

Price Code: A03 


\section{HEAT TRANSFER MEASUREMENTS AND PREDICTIONS ON A POWER GENERATION GAS TURBINE BLADE}

\author{
Paul W. Giel \\ Dynacs Engineering Co., Inc. \\ NASA Glenn Research Center \\ Brook Park, Ohio 44142 USA \\ Email: Paul.W.Giel@grc.nasa.gov
}

\author{
Ronald S. Bunker \\ Corporate Research and Development \\ General Electric Corporation \\ Schenectady, New York, 12301 USA \\ Email: bunker@crd.ge.com
}

\author{
G. James Van Fossen \\ Robert J. Boyle \\ NASA Glenn Research Center \\ Cleveland, Ohio, 44135 USA \\ Email: Gerald.J.VanFossen@grc.nasa.gov \\ Email: Robert.J.Boyle@grc.nasa.gov
}

\begin{abstract}
Detailed heat transfer measurements and predictions are given for a power generation turbine rotor with 129 deg of nominal turning and an axial chord of $137 \mathrm{~mm}$. Data were obtained for a set of four exit Reynolds numbers comprised of the design point of $628,000,-20 \%,+20 \%$, and $+40 \%$. Three ideal exit pressure ratios were examined including the design point of $1.378,-10 \%$, and $+10 \%$. Inlet incidence angles of $0 \mathrm{deg}$ and $\pm 2 \mathrm{deg}$ were also examined. Measurements were made in a linear cascade with highly three-dimensional blade passage flows that resulted from the high flow turning and thick inlet boundary layers. Inlet turbulence was generated with a blown square bar grid. The purpose of the work is the extension of threedimensional predictive modeling capability for airfoil external heat transfer to engine specific conditions including blade shape, Reynolds numbers, and Mach numbers. Data were obtained by a steady-state technique using a thin-foil heater wrapped around a low thermal conductivity blade. Surface temperatures were measured using calibrated liquid crystals. The results show the effects of strong secondary vortical flows, laminar-to-turbulent transition, and also show good detail in the stagnation region.
\end{abstract}

\section{NOMENCLATURE}

$A$ heater area $\left[\mathrm{m}^{2}\right]$

$C_{x}$ blade axial chord [mm]

$d \quad$ leading edge diameter [mm]

$h$ heat transfer coefficient $\left[\mathrm{W} / \mathrm{m}^{2} \cdot \mathrm{K}\right]$

$\mathrm{Fr}$ Frossling number, $\mathrm{Fr}=\mathrm{Nu} \cdot\left(d / C_{x}\right) / \sqrt{\operatorname{Re}_{d, i n}}$

$I$ heater current [Amps]

$K$ pressure gradient parameter, $K=\left(\mu / \rho U^{2}\right)(d U / d s)$

$k$ thermal conductivity $[\mathrm{W} / \mathrm{m} \cdot \mathrm{K}]$

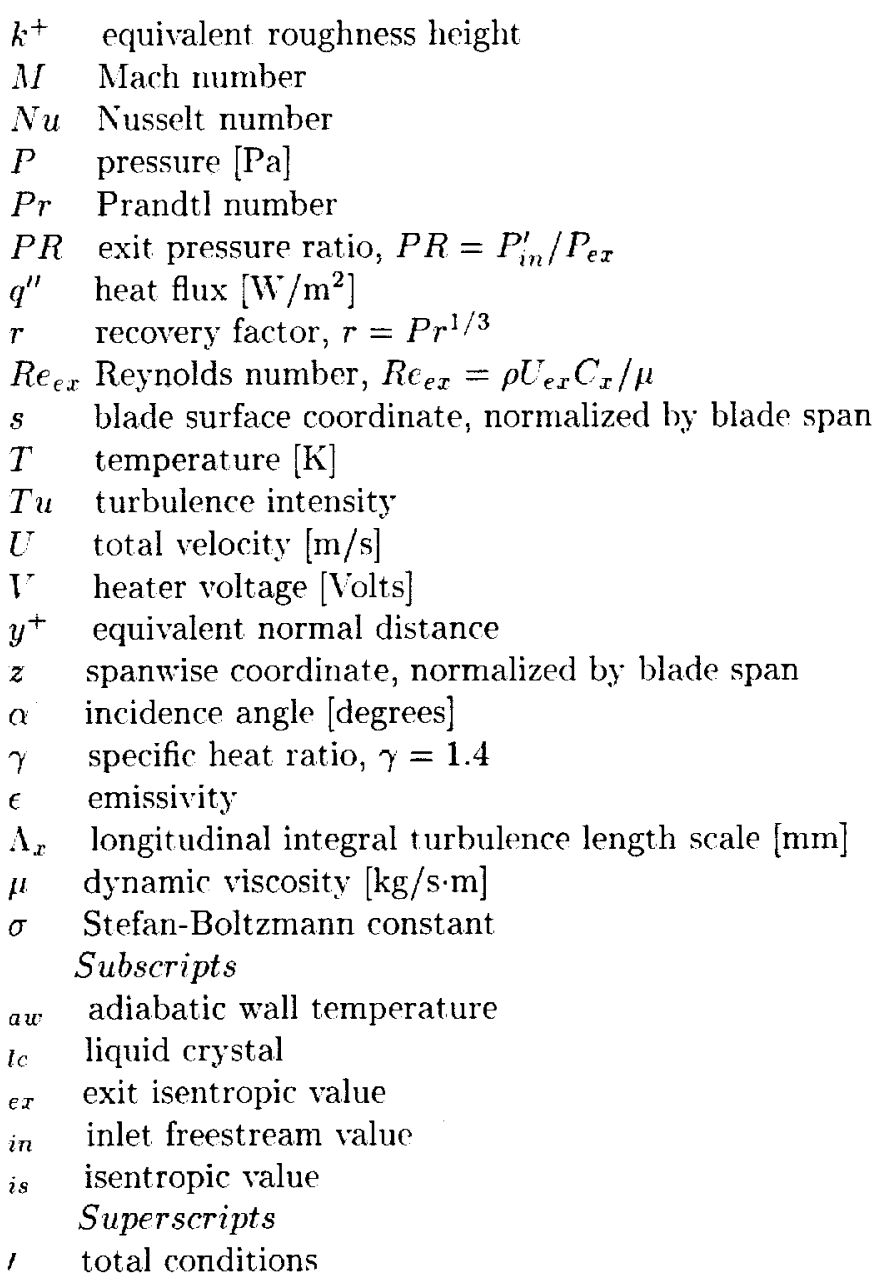




\section{INTRODUCTION}

Turbine blade aerodynamics is generally given a high degree of analysis prior to commitment for fabrication. This attention to detail is carried through to the manufacturing specifications and quality inspections in the form of dimensional accuracies demanded of both the airfoils and the rotor disks. While a substantial amount of data exists concerning the effects of blade incidence angle, Reynolds number, and pressure ratio (loading) on aerodynamics, less information is available on the associated airfoil heat transfer distributions for off-design conditions. Computational Fluid Dynamics (CFD) is increasingly being relied upon in the design and analysis of gas turbine components. The need to predict heat transfer along with aerodynamics during the design of turbine blades greatly complicates these analyses. Thus, the heat transfer predictive capability of CFD currently lags that of aerodynamics. Heat transfer data is therefore needed both to assess the effects of various flow parameters and to improve CFD analyses so that these effects can be accurately predicted.

Arts et al., (1998) studied incidence, Reynolds number, and exit Mach number effects on heat transfer, but with midspan thermocouples only. Incidence was varied over a range of $-14 \mathrm{deg}$ to $+11 \mathrm{deg}$. Camci and Arts (1991) also examined incidence effects on a film-cooled heat transfer test blade, but again only at midspan. The threedimensional nature of the flow and heat transfer indicates that a full-blade understanding is needed, not just a twodimensional understanding at midspan. Previous studies have shown that rotor geometries in linear cascades provide good midspan data as compared to their rotating equiralents. See, for example, Baughn et al. (1995) or Guenette et al. (1989). Also, Graziani et al. (1980) studied the effects of thick and thin endwall boundary layers on rotor heat transfer in a low speed linear cascade. Blair (1994) measured heat transfer in a low speed facility on a rotating blade that had the same midspan section as the blade of Graziani et al. (1980). Similar three-dimensional heat transfer patterns were observed at and below midspan of those two tests, validating the use of linear cascades for these types of heat transfer studies. Dunn et al. (1994) measured rotor heat transfer at discrete chordwise and spanwise locations in a shock tube facility at engine-typical gas-to-wall temperature ratios and Mach numbers. These measurements were on engine-size hardware using heat flux gauges. Consequently, the resolution was less than for the large scale facility measurements.

Detailed heat transfer data at conditions approximating those in actual engines are needed to assess flow parameter effects and to verify CFD predictive analyses. Variations in flow parameters often have an impact on secondary flows and thus on the three-dimensional nature of the heat trans-

\section{Parameter \\ axial chord \\ pitch \\ span \\ $d$, leading edge $10.6 \mathrm{~mm}$ (0.417 in.) \\ turbulence grid $25.4 \mathrm{~mm}$ square bar \\ blade passages 11 \\ ( $d=2 \times$ minimum radius of curvature $)$}

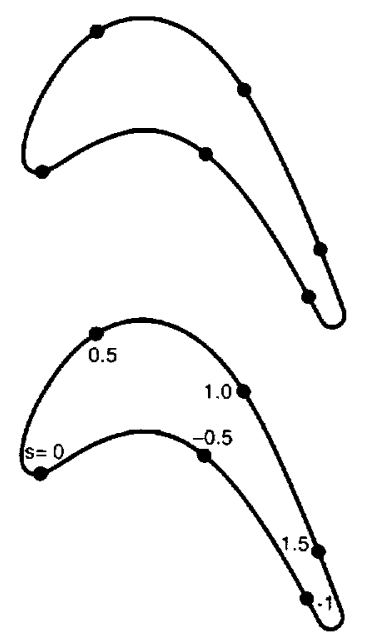

Figure 1. Test Blade Geometry

fer distribution. Data is therefore needed all over the blade surface, not just at midspan.

The blade geometry of the present study is representative of an aerodynamically upgraded first stage turbine blade midspan section for an established G.E. power generation turbine. In an effort to continuously improve turbine performance, output, and durability, older designs may be upgraded in a number of ways, including aerodynamics, cooling, materials, and sealing. The present design is used in a non film-cooled application for which knowledge of the external convective heat transfer distribution is desired, both for design validation and improvement of predictive capabilities. The turbine blade is for a $2000^{\circ} \mathrm{F}$ class machine. The midspan section design operating condition for full power yields an airfoil exit Reynolds number of 628,000 with an inlet Mach number of 0.41 and an inlet total to exit static pressure ratio of 1.378 , corresponding to an isentropic exit Mach number of 0.693 . The airfoil section is entirely subsonic and has a total turning of 129 deg with a design inlet flow angle of $61.3 \mathrm{deg}$. The blade geometry is shown in Fig. 1 along with geometric details. Surface distance coordinates are also shown on the blade.

The present study obtains both airfoil pressure and heat transfer coefficient distributions for a parameter design space which represents a set of limits that could be imposed by design uprate targets, manufacturing cost reductions, or operational demands. Incidence angle has been altered from -2 to $+2 \mathrm{deg}$, exit Reynolds number from $-20 \%$ to $+40 \%$, and pressure ratio from $-10 \%$ to $+10 \%$. These pressure ratio variations correspond to isentropic exit Mach numbers ranging from 0.563 to 0.794 . The set of data produced in this study serves as a test of CFD predictive capability for an actual airfoil design space. The primary objective of this 


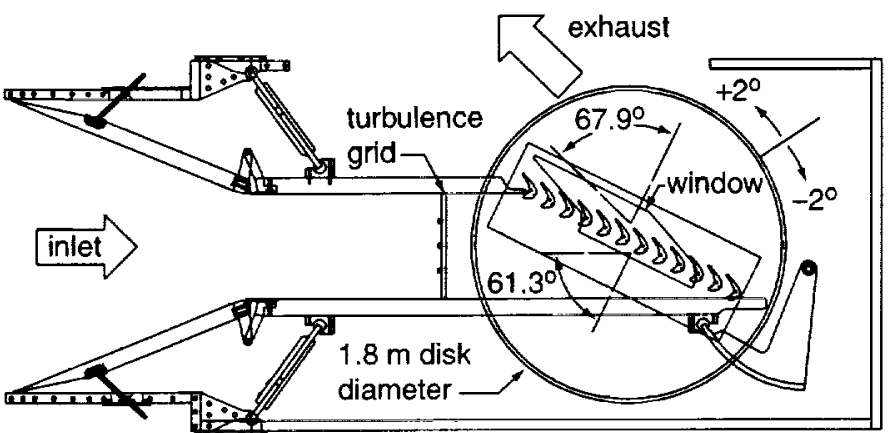

Figure 2. Transonic Turbine Blade Cascade Facility

research is the continued extension of three-dimensional predictive modeling techniques for airfoil external heat transfer through the acquisition of full-surface blade data. The airfoil and flow conditions of the present study model those of an engine design, including a moderate level of surface roughness as provided by the test method. The airfoil shape is distinctly different than one previously tested in the same facility, thus providing a new CFD test case for previously validated predictive techniques. The CFD comparisons are challenged further by the additional variation of incidence angle and by the relatively low Reynolds numbers. The CFD predictions, when compared to the measurements, point out areas where modeling improvements are needed. Liquid crystal surface temperature measurement techniques are capable of obtaining detailed data over an entire surface and were therefore chosen for the present study.

\section{DESCRIPTION OF FACILITY}

\section{Cascade Description}

The NASA Glenn Research Center Transonic Turbine Blade Cascade provides heat transfer and aerodynamic data to verify CFD analyses. The facility can and has been used to test over wide, independent ranges of Reynolds number and Mach number. High pressure, ambient temperature air can be throttled to an inlet pressure that can be varied from the exit pressure to over one atmosphere. The facility is designed for independent control over exhaust pressure which can be varied from the inlet pressure down to $15.9 \mathrm{kPa}$ $(2.3 \mathrm{psia})$. A two-dimensional view of the facility is shown in Fig. 2. The heat transfer measurement blade was the sixth blade from the left, and the pressure measurement blades were the fifth and sixth.

While the blade and cascade geometries are twodimensional, the blade passage flows are highly threedimensional due to the turning and to the thick boundary layers developed on the long cascade inlet. The thickness of each endwall boundary layer was approximately $35 \%$ of the half-span, as measured approximately one axial chord upstream of the blade row. The thick boundary layers and high flow turning resulted in spanwise flow variations as large as those seen in rotating turbines. Sec, for example, Joslyn and Dring (1992) or Thulin et al. (1982). These variations result from secondary flows, and accurately predicting them is a significant test of a three-dimensional analysis.

Inlet turbulence was produced using a square bar, bidirectional grid upstream of the blade row. The grid was made of $25.4 \mathrm{~mm}$ ( 1 inch) square hollow bars with 75 uniformly spaced $3.2 \mathrm{~mm}$ (1/8 in.) diameter holes blowing air in the upstream direction. One bar extended between the inlet boards at midspan and three bars spaced six bar dimensions apart were placed spanwise as shown in Fig. 2 . The total mass flow from the grid was $0.68 \mathrm{~kg} / \mathrm{s}(1.5 \mathrm{lb} \mathrm{m} / \mathrm{s})$ for all cases, corresponding to $11 \%$ of the cascade mass flow at the design exit Reynolds number. The open area of the grid was $74 \%$ and it was located $1.10 \mathrm{~m}$ ( $43 \mathrm{in}$.) upstream of the heat transfer measurement blade. It was positioned normal to the inlet flow as shown in Fig. 2. An acrodynamic probe measurement slot was located an axial distance of $127 \mathrm{~mm}$ in front of the cascade face. The inlet turbulence level measured there was approximately $9 \%$. Using the correlation of Baines and Peterson (1951), this can be expected to decay to about $7.5 \%$ at the cascade face. The longitudinal, integral turbulence length scale was measured to be $\Lambda_{x}=22 \mathrm{~mm}$. Pitchwise and spanwise surveys of mean velocity, $T u$, and length scale were made in the probe slot over several blade passages. The results of those measurements can be found in a previous study by Giel et al. (1999). The blades of the current study have the same pitch and are located at the same pitchwise locations as those of the previous study.

Figure 2 shows the test section mounted on a large rotatable disk. The disk can be rotated $+15 \mathrm{deg}$ to $-30 \mathrm{deg}$ to accommodate a blade with a different inlet flow angle than the original as well as to vary the incidence angle. $\mathrm{U}_{\mathrm{p}}$ stream inlet boards were used, but the facility uses no exit tailboards. Endwall static pressure measurements and other flow field aerodynamic probe measurements all showed excellent periodicity in at least the center three blade passages (see Giel et al., 1996).

\section{Pressure Measurement Blade Description}

The two blades forming passage 5 were instrumented for pressure measurements. Blade 5 had 20 static pressure taps at $10 \%$ span and 20 more at $25 \%$ span. Blade 6 had 40 taps at midspan. The tap diameters were $0.5 \mathrm{~mm}$ (0.020 in.). 
The blade in position 6 was fabricated from low conductivity foam for heat transfer measurements. The undersized foam core was placed in a mold and gelcoat epoxy was cast around it. The outcr epoxy shape was itself undersized by $152 \mu \mathrm{m}(0.006 \mathrm{in}$.) to accommodate a $25 \mu \mathrm{m}(0.001 \mathrm{in}$.) Inconel thin foil heater and a $127 \mu \mathrm{m}(0.005 \mathrm{in}$.) double-faced adhesive layer. The single sheet heater covered the entire blade except on the trailing edge circle. Two thin-film thermocouples were glued to the heater sheet at $z=0.25$, one on the pressure surface at $s=-0.29$ and one on the suction surface at $s=1.51$. These were used for overheat control and for liquid crystal temperature verification. Flat black paint was sprayed over the outer surface and a $25 \times 25 \mathrm{~mm}$ ( $1 \times 1 \mathrm{in}$.) grid of white dots was painted on for location reference. Finally, chiral nematic, micro-encapsulated liquid crystals were sprayed onto the outer heater surface. A temperature calibration plate, instrumented with a thermocouple, and a roughness measurement plate were sprayed at the same time. The liquid crystal yellow-line temperature was calibrated with the calibration plate and verified during data acquisition with the two blade surface-mounted thermocouples. Both ends of the measurement blade were made of $12.7 \mathrm{~mm}$ (0.50 in.) thick nickel-plated copper, cut out in the shape of the blade, and were used as buss bars to supply DC electrical power to the heater. The heater foil extended over the copper ends and was tack welded to them. Hollow studs extended from the copper, through the acrylic windows, and were used for mounting and for electrical connections. They were also connected through racuum tubing to the exhaust section of the facility to approximately equalize the pressure inside and outside of the blade, preventing damage to the surface when the test section pressure was changed. Both endwalls were $63.5 \mathrm{~mm}$ (2.50 in.) thick clear acrylic for optical access. An outline of the window is shown in Fig.2.

A profilometer was used to measure several 5 -mm traces on the roughness measurement plate after the liquid crystals were applied. A $60 \times$ photomicrograph showed that the profilometer stylus did not alter the crystals. The arithmetic mean roughness was $6.5 \mu \mathrm{m}$ and the r.m.s. roughness was $7.8 \mu \mathrm{m}$. The average peak-to-peak distance was $97 \mu \mathrm{m}$. The equivalent roughness height was estimated to be $7 \mu \mathrm{m}$. The maximum normalized roughness height, $k^{+}$, was estimated to be 1.2 , so from a surface roughness standpoint the blade surface was hydraulically smooth. This tested condition is thus not typical of in-service operating blade roughness.

\section{Blade Static Pressure Measurements}

Surface static pressures were measured independently from the heat transfer measurements using a separate blade set. The two blades forming passage 5 were instrumented with 80 static pressure taps. The pressure taps were scanned at a rate of once per second with an electronically scanned measurement system. Fifteen scans were averaged. The inlet total pressure was measured as the average of three midspan Kiel probes upstream of passages 4,7 , and 8. The probes were located an axial distance of $127 \mathrm{~mm}$ (5.0 in.) ahead of the cascade face. More details of the blade static pressure measurement techniques are given by Giel et al. (1990).

\section{Heat Transfer Measurements}

The selections of liquid crystal yellow line temperatures and color band widths were made subject to several constraints. The crystal temperature was chosen to be as high as possible to minimize uncertainty without exceeding the $80^{\circ} \mathrm{C}\left(175^{\circ} \mathrm{F}\right)$ material limit of the double-faced adhesive. This limit was approached in regions of minimum heat transfer when the heater power was increased to make measurements in regions of maximum heat transfer. A crystal temperature $14^{\circ} \mathrm{C}\left(25^{\circ} \mathrm{F}\right)$ above the inlet total temperature typically met both criteria. Because the inlet temperature varied from day to day, two crystals were mixed and sprayed onto the surface. Data were then obtained from whichever crystal offered a higher $\Delta T$ without exceeding the material limits. Often, a combination of crystal temperatures were used to map the entire surface. Narrower band width crystals provide better resolution in regions of very low gradients but the yellow line could become too thin to be clearly visible in high gradient regions. Crystals with full color bandwidths of $\pm 2^{\circ} \mathrm{C}$ were found to be a good compromise for the current measurements.

The following procedure was used to obtain the heat transfer data: Flow conditions were established and the heater power was increased until the first yellow isotherm was visible. When steady state conditions were achieved, typically within 5 minutes, data recording of voltage, current, and flow conditions was initiated. The blade surface was simultaneously photographed with four $35 \mathrm{~mm}$ still cameras using color slide film. Each camera photographed a subset of the blade surface, with some overlap between views. High speed photographic strobes were used to prevent radiative heating of the liquid crystals. The strobes were mounted as close as possible to the camera lens to minimize differences between viewing and illumination angles. Moffat (1990) showed that micro-encapsulated crys- 
tals are less sensitive to illuminating and viewing angles than non-encapsulated crystals. No differences in isotherm location were detected between overlapping photographs. Heater power was then increased to move the isotherms and the process was repeated until the entire blade surface was mapped. Eighteen power levels were typically used for each flow condition.

The difference between the surface temperature and the local adiabatic wall temperature was used to define the heat transfer coefficient. In regions where data were available from both crystals, agreement between the crystals verified that the correct definition of $h$ was used and that the adiabatic wall temperature was reasonably accurate.

The following procedure was used to reduce the heat transfer data. The photographic slide images were projected onto paper and the reference dot pattern and the isotherms were sketched. The slide image dot pattern was aligned for subsequent isotherms. Separate sketches were made for each camera and crystal temperature. These isotherm sketches were then digitized, with between 3000 to 5000 digitized points for each flow condition. A grid having five times the resolution of the blade dot pattern painted was laid over the blades and photographed. Every fifth point on the grid photograph was aligned with the dots in the data photographs. The finer resolution coordinates were then used to interpolate each digitized point to $(s, z)$ unwrapped blade coordinates. This procedure corrected for distortions due to blade curvature and viewing angles.

The local surface heat flux, $q^{\prime \prime}$, was determined from the heater voltage and current, then corrected for radiative heat loss:

$$
q^{\prime \prime}=\frac{T^{r} \cdot I}{A}-\epsilon \sigma\left(T_{l c}^{4}-T_{a u}^{4}\right)
$$

With $\epsilon=0.98$, radiative losses were at most $6 \%$ of the net heat flux and typically much less. The heat transfer coefficient and the Nusselt number were defined as follows:

$$
h=\frac{q^{\prime \prime}}{\left(T_{l c}-T_{a w}\right)} \quad \text { and } \quad N u=\frac{h \cdot C_{x}}{k\left(T_{i n}^{\prime}\right)}
$$

The local adiabatic wall temperature, $T_{a u}$, is:

$$
\frac{T_{a u}}{T_{i n}^{\prime}}=r+\frac{1-r}{1+0.5(\gamma-1) M_{i s}^{2}}
$$

- The choice of $T_{a u}$ as the convective driving temperature ensures that $h$ and $N u$ are reasonably independent of the thermal boundary condition, specifically, independent of the particular choice of liquid crystal temperature. The inlet total temperature, $T_{i n}^{\prime}$, was determined by a mass weighted average of the main flow and the turbulence grid flow. Two additional total temperature probes were located an axial distance of $127 \mathrm{~mm}$ (5.0 in.) ahead of the cascade face and agreed with the mass weighted average to within the measurement uncertainty: The local adiabatic wall temperature was needed at each digitized point in order to calculate the heat transfer coefficient. This information was interpolated from CFD calculations of blade surface static pressure which will be shown to agree well with measured values. The calculated values provided significantly better spatial resolution than was available from the experimental data. The isentropic Mach number, $M_{i s}$, was determined from CFD calculations, and a recovery factor of $r=\mathrm{Pr}^{1 / 3}$ was used everywhere. The data were triangulated for contour plotting and interpolated onto constant span lines of $15 \%, 25 \%$, and $50 \%$ for line plotting.

\section{Uncertainty Analysis}

An uncertainty analysis was performed using the method of Kline and McClintock (1953). The major sources of uncertainty are the adiabatic wall temperature; $\delta T_{a u}= \pm 1.0^{\circ} \mathrm{C}\left( \pm 1.8^{\circ} \mathrm{F}\right)$ and the liquid crystal temperature, $\delta T_{l c}= \pm 0.5^{\circ} \mathrm{C}\left( \pm 0.9^{\circ} \mathrm{F}\right)$. At the temperature differences and the relatively low Mach numbers of the current study, the uncertainty in pressure measurements, the differences between measured and calculated pressures, and the interpolations are minor contributors to the overall uncertainty of $T_{a w}$ as compared to the uncertainty in $T_{i n}^{\prime}$. The uncertainty in $T_{a u}$ for the same reason assumes no uncertainty in the recovery factor, $r$, although it is not precisely known as shown by Schlichting (1979). Other less dominant sources of uncertainty such as the heater voltage and current, $\delta \mathrm{T} / \mathrm{V}=\delta I / I=1 \%$, and the heater length and width, $\delta L / L=2 \%$ and $\delta \Pi / \%=1 \%$, were included in the analysis. The overall uncertainty in $N u$ was determined to be less than $13 \%$ for all cases and was typically much less. Because the uncertainty varied with specific conditions, maximum values for each case will be presented with the results.

Another possible source of bias uncertainty is thermal conduction within the measurement blade. A twodimensional finite-difference conduction analysis was performed to examine this error. A typical, measured midspan $h$ distribution was prescribed on the outer surface, and temperatures within the blade were calculated. A thermal conductivity of $0.2 \mathrm{~W} / \mathrm{m} \cdot \mathrm{K}$ was used for both the foam and the gelcoat epoxy. Conduction within the blade tended to increase $q^{\prime \prime}$ in cooler regions and decrease it in hotter re- 


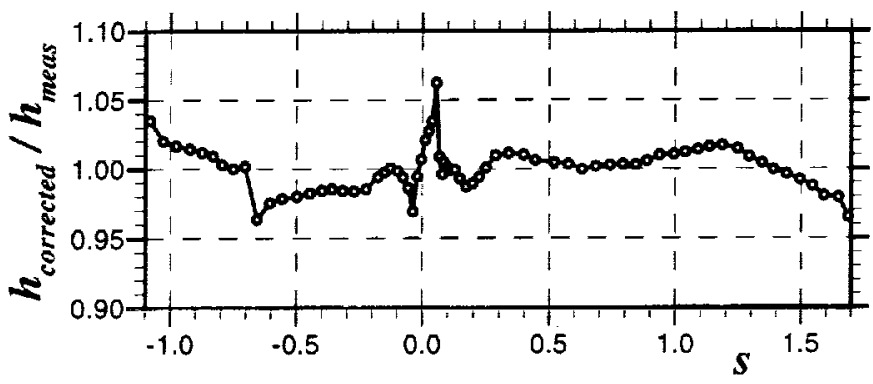

Figure 3. Midspan Heat Conduction Analysis

gions. Corrected values of $h$ were then determined from Eq. (1). Figure 3 shows that the maximum conduction error is approximately $6 \%$, which is within the overall uncertainty. To assess the validity of the conduction analysis, the finite-difference grid resolution was doubled in the leading edge region. The finer grid results were essentially identical to the results shown in Fig. 3.

\section{CFD ANALYSIS}

To illustrate where analysis improvements are needed, baseline CFD results were done using the three-dimensional Navier-Stokes analysis code, RVC3D, described by Chima and Yokota (1990) and by Chima (1991). C-type grids were generated using the method of Arnone et al. (1992). Predictions were made using a $313 \times 49 \times 49$ grid with a near wall spacing, $y_{1}^{+}<1.190$ grid lines were wrapped around the blade. A uniform wall temperature of $1.07 \times T_{i n}^{\prime}$ was specified on the heated blade and a uniform wall temperature of $1.0 \times T_{i n}^{\prime}$ was specified on the unheated endwall. The flow over much of the blade was expected to be turbulent so little difference would be expected from uniform heat flux and uniform wall temperature heat transfer solutions (Kays and Crawford, 1980). This was verified by running a calculation with a wall temperature boundary distribution consistent with one that would be present for a uniform heat flux. The two solutions agree very closely. All of the analyses shown herein assumed midspan symmetry. The solutions were mirrored across midspan for easier comparison with the full-span experimental data.

A two-layer algebraic turbulence model, described by Chima et al. (1993), was used. The model was designed to avoid spurious inner-to-outer region crossovers, which sometimes occurs with Baldwin-Lomax type algebraic turbulence models. The inner and outer blending modification described in Giel et al. (1999) was again used. An algebraic model, Smith and Kuethe (1966), to account for the effects of freestream turbulence on laminar heat transfer was used. This model was found by Giel et al. (1999), and by Boyle and Simon (1999) to improve the agreement of pre- dicted heat transfer with the experimental data. However, for the results presented herein this model did not improve the agreement with data. Predictions are shown with and without this laminar augmentation model to illustrate the significance of the model for heat transfer predictions.

Transition start was specified using Mayle's (1991) model. $T u$ at transition start was the upstream $T u$ times the ratio of the upstream velocity to the local isentropic velocity. This approach was found by Boyle and Simon (1999) to give an accurate prediction for the start of rotor blade transition. The transition length model of Boyle and Simon (1999) was used. This model is an extension of the one by Solomon et al. (1995) to include Mach number effects.

\section{BLADE STATIC PRESSURE RESULTS}

Figure 4 shows sample measured and calculated isentropic surface Mach number distributions on an unwrapped blade surface. Fig. 4(a) shows calculated contours of $M_{\text {is }}$ for the design case. Figs. 4(b-d) show comparisons with data for variations in $P R$. In all cases, the comparison with data is excellent. The surface contour plot shows the strong three-dimensionality of the flow, as evidenced by the distorted suction surface contours caused by the horseshoe/passage vortices. These rortices are seen to exit the blade row at about $25 \%$ span. The line plots also show that the $25 \%$ span Mach number distribution exceeds that of the $10 \%$ and $50 \%$ on the back half of the suction surface. No decelerating flow regions are seen on the suction surface until after the throat at $s \approx 1.0$ where very slight deceleration occurs on the uncovered portion of the blade. Deceleration is also seen on the pressure surface just downstream of the leading edge, extending to $s \approx-0.4$. These regions are noted because of their potential implications on transition and thus on heat transfer. The calculated values were used for heat transfer data reduction because they provided significantly better spatial resolution than was available from the experimental data.

\section{EXPERIMENTAL HEAT TRANSFER RESULTS}

Data and CFD calculations will be presented as Nusselt number contours on the unwrapped blade surface and as line plots at $15 \%, 25 \%$, and $50 \%$ span. Discussion on the experimental data all will be presented first, followed by a discussion of the calculated results. Gray areas on the data contour plots indicate regions where data were not available. The copper buss bars will also be evident in the data plots as regions near the endwalls where no data were available. The CFD calculations were made with a uniform temperature specified on the entire blade and did not model the 


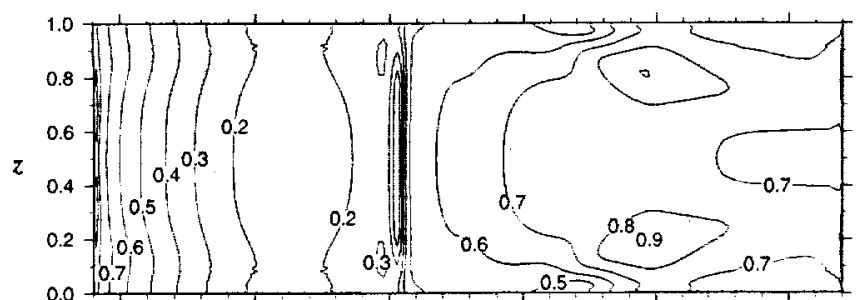

(a) calculated $M_{\text {is }}$ contours at design $P R$

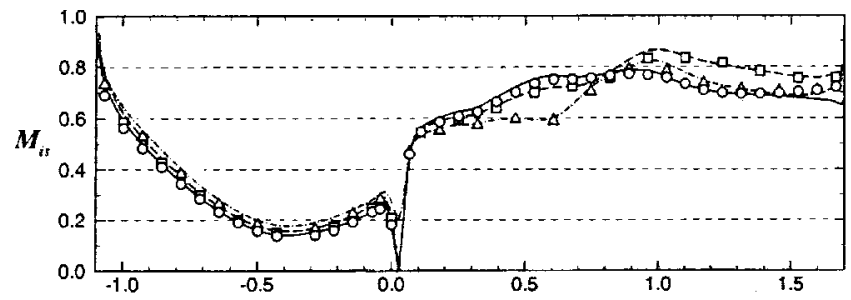

(b) loading comparison at design $P R$

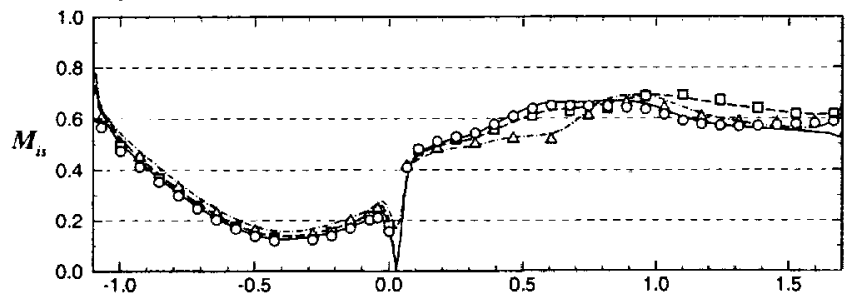

(c) loading comparison at $-10 \% P R$

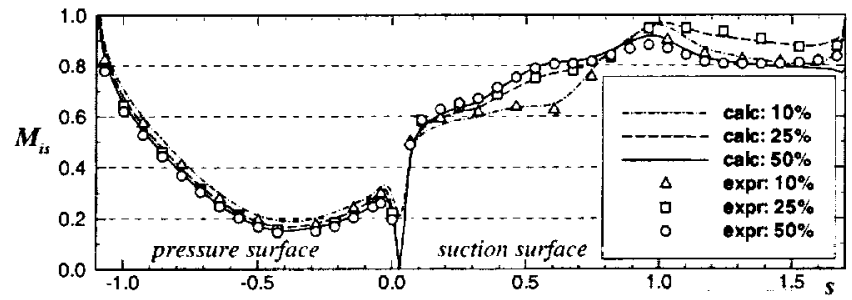

(d) loading comparison at $+10 \% P R$

Figure 4. Measured and Calculated Blade Loadings

buss bar thermal boundary condition. Lines showing their locations are included in the contour plots for reference. It should be noted that no midspan symmetry was assumed in presenting the experimental data; measured symmetry is typically excellent, but minor differences can be seen. The first case to be presented will be the baseline case, obtained at the design flow conditions. Subsequent cases are grouped to examine the effects of Reynolds number, pressure ratio, and incidence angle.

The measured flow conditions for the eight heat transfer cases are listed in Table 1 . Repeatability of $R e_{\varepsilon x}$ was within $1 \%$ for all cases and repeatability of $P R$ was within $0.2 \%$. As mentioned earlier, $N u$ uncertainty depended primarily on the difference between the air temperature and the liquid crystal temperature. The variations in uncertainty shown in Table 1 resulted from day-to-day variations in inlet air temperature. $R e_{d, i n}$ is included in the table for discussion
Table 1. Description of Blade Heat Transfer Cases

\begin{tabular}{|c|c|c|c|c|c|c|c|}
\hline Case & $R e_{r . x}$ & $P R$ & $\alpha_{i n}$ & $R e_{d i n}$ & $M_{i n}$ & $\begin{array}{c}\text { peak } \\
F r\end{array}$ & $\begin{array}{c}\text { max } N u \\
\text { uncert }\end{array}$ \\
\hline 1 & 022.100 & 1.376 & $0.0^{\circ}$ & 29,939 & 0.371 & 0.828 & $9.8 \%$ \\
2 & 500,800 & 1.381 & $0.0^{\circ}$ & 24.271 & 0.376 & 0.950 & $7.6 \%$ \\
3 & 751,600 & 1.376 & $0.0^{\circ}$ & 35,945 & 0.369 & 0.866 & $7.5 \%$ \\
4 & 880,400 & 1.378 & $0.0^{\circ}$ & 42,151 & 0.370 & 0.869 & $10.8 \%$ \\
5 & 626,900 & 1.240 & $0.0^{\circ}$ & 30,801 & 0.327 & 0.839 & $12.4 \%$ \\
6 & 625,700 & 1.513 & $0.0^{\circ}$ & 29,068 & 0.389 & 0.998 & $7.7 \%$ \\
7 & 626.700 & 1.377 & $-2.0^{\circ}$ & 27,498 & 0.335 & 0.899 & $9.9 \%$ \\
8 & 629.500 & 1.376 & $+2.0^{\circ}$ & 33.250 & 0.414 & 0.877 & $7.4 \%$ \\
\hline
\end{tabular}

of the stagnation point heat transfer. An inlet Reynolds number based on axial chord can be calculated from this by multiplying by $C_{x} / d=13.0$.

\section{Baseline Case}

Figure 5 shows the measured and predicted Nusselt number distribution at the design flow condition of $R e_{e x}=$ $628,000, P R=1.378$, and $\alpha=0 \mathrm{deg}$. The pressure side data shows a very flat, two-dimensional $N u$ distribution with a slight increase at the trailing edge, possibly indicating the start of transition. A leveling of $N u$ near $s=-0.1$ can be seen in Fig. 5(c). Just downstream of the stagnation point, the data shows no indication of transition, despite the high freestream turbulence intensity and the decelerating flow region, $-0.4 \leq s \leq-0.1$. The heat transfer data, however, may not be a good indicator of transition. The low velocities could counteract the effects of transition, leading to uniform $N u$ levels. This will be verified with comparisons at different Reynolds numbers.

The stagnation region is clearly evident in the figure, with a somewhat stecper gradient on the pressure side than on the suction side. Table 1 lists peak Frossling numbers, defined as $F r=N u \cdot\left(d / C_{x}\right) / \sqrt{R e_{d, i n}}$. The peak Nusselt numbers were corrected for blade conduction by a factor of 1.06 as suggested by Fig. 3. This correction was only applied to the peak data of Table 1 where the conduction error was largest, not to the the remainder of the data where it has less effect. An ellipse with an aspect ratio of 1.5 was found to best describe the blade leading edge. Van Fossen et al. (1995) studied stagnation region heat transfer on isolated elliptical leading edges. They indicate that a laminar Frossling number of 0.870 is appropriate for this aspect ratio. They also developed the following correlation for a stagnation point turbulent augmentation factor:

$$
\frac{F r_{T u}}{F r_{l a m}}=0.0085 \sqrt{T u \operatorname{Re}_{d}^{0.8}\left(\frac{\Lambda_{x}}{d}\right)^{-0.574}}+1.0
$$




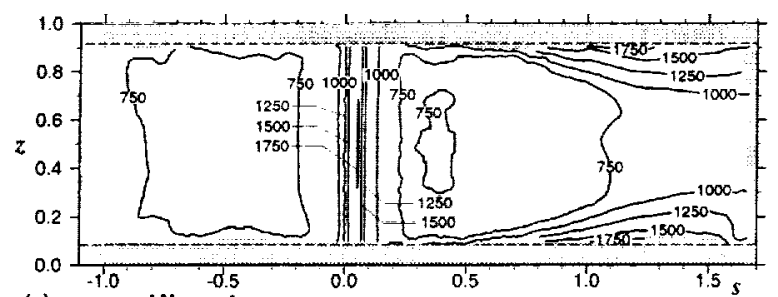

(a) measured Nu contours

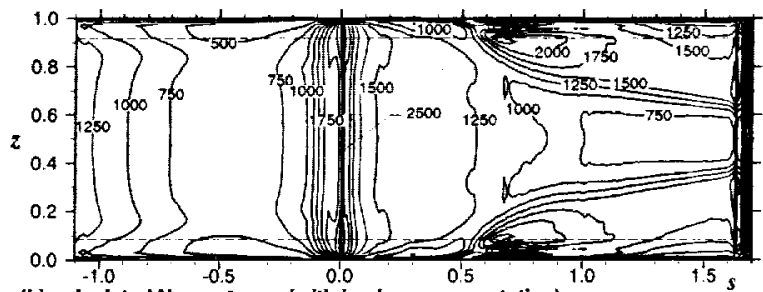

(b) calculated Nu contours (with laminar augmentation)

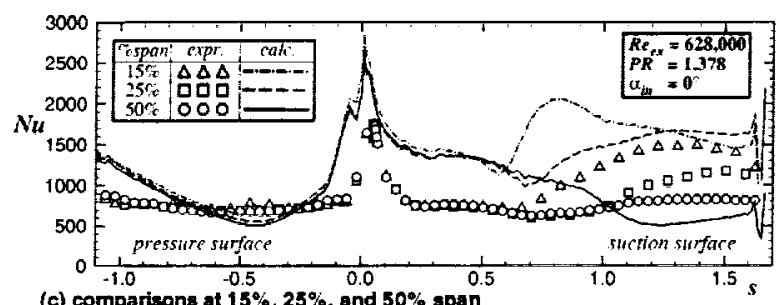

(c) comparisons at $15 \%, 23 \%$, and $50 \%$ span

Figure 5. Heat Transfer Distributions - Case 1

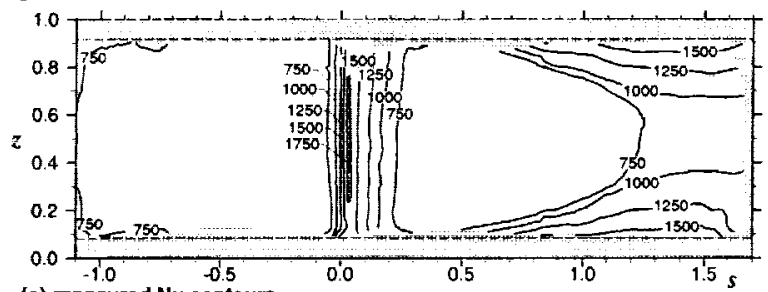

(a) measured Nu contours

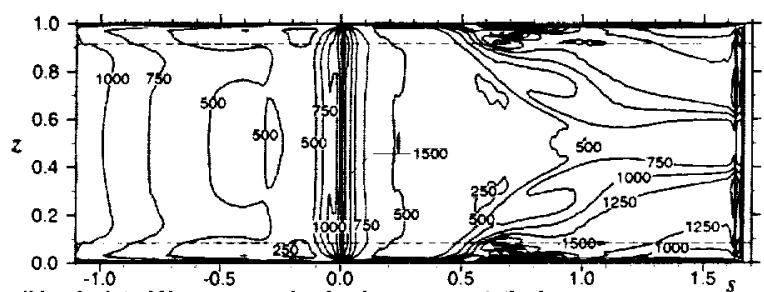

(b) cakulated Nu contours (no laminar augmentation)

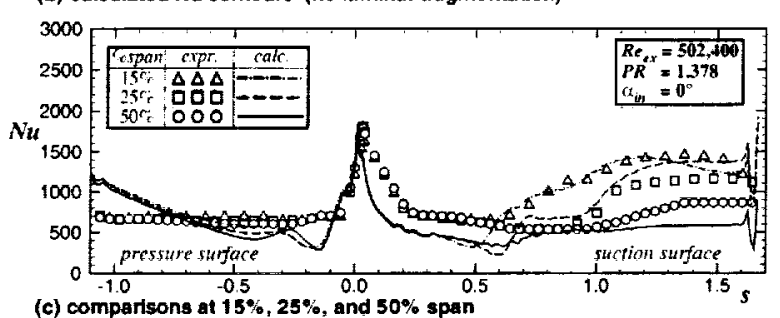

(c) compartsons at $15 \%, 25 \%$, and $50 \%$ span

Figure 6. Heat Transfer Distributions - Case 2

Despite the relatively high $T u$ of the current study, this correlation predicts an augmentation factor of only 1.12 , and thus a Frossling number of 0.976 . The low augmentation results from the low Reynolds number and high $\Lambda_{x} / d$ ratio. The measured value of 0.828 is about $15 \%$ less than

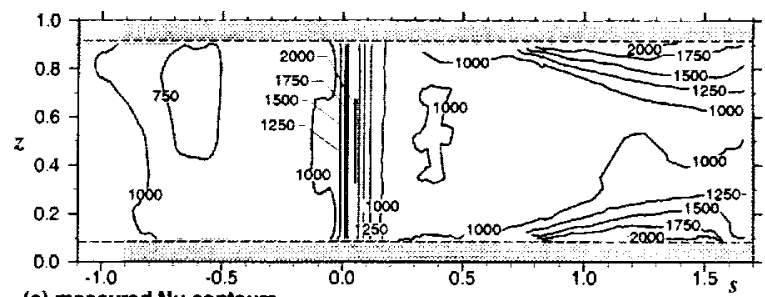

(a) measured Nu contours

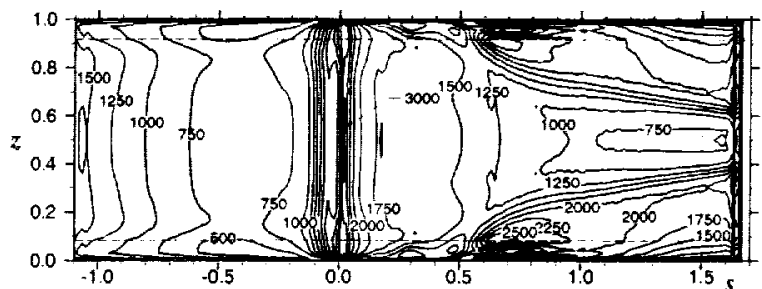

(b) calculated Nu contours (with laminar augmentation)

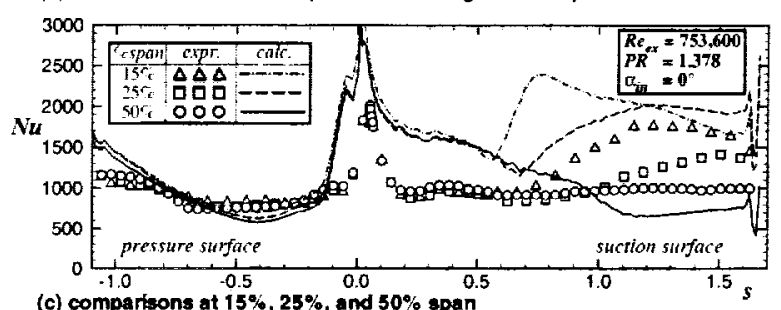

(c) comparisons at $15 \%, 25 \%$, and $50 \%$ span

Figure 7. Heat transfer distributions - Case 3

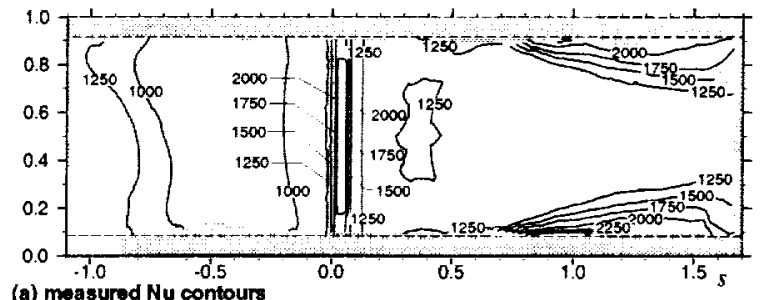

(a) measured Nu contours

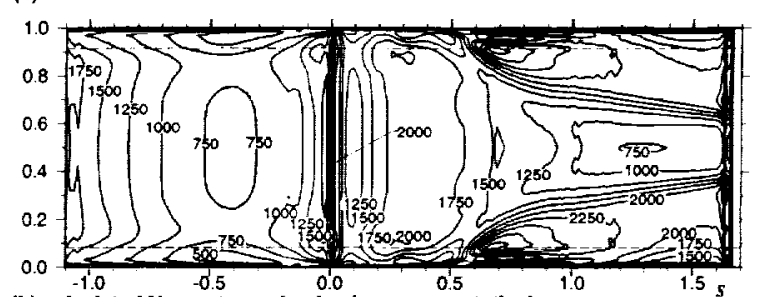

(b) calculated Nu contours (no laminar augmentation)

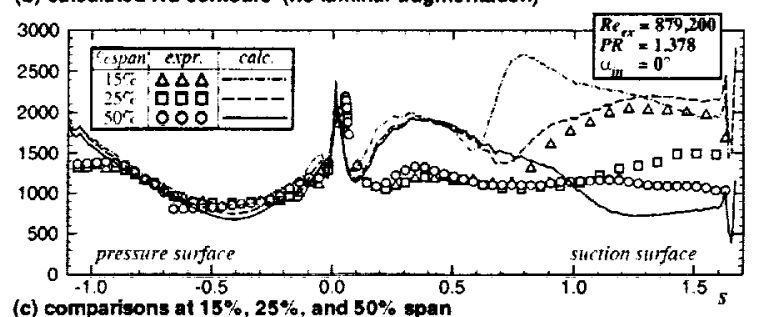

Figure 8. Heat Transfer Distributions - Case 4

the correlation predicts. This could be due to an underprediction of conduction effects or fundamental differences between heat transfer rates on isolated ellipses at zero angle of attack and a cascade of highly loaded blades.

Just downstream of the stagnation region on the suc- 


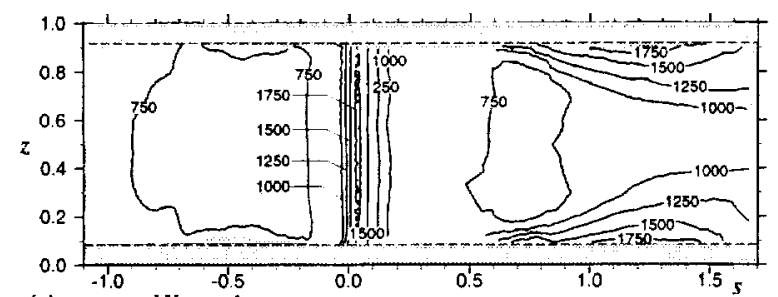

(a) measured Nu contours

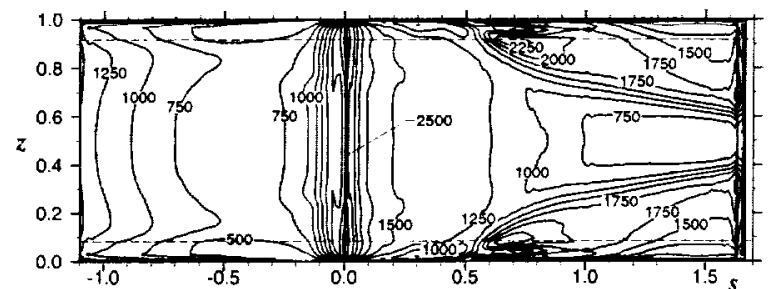

(b) calculated Nu contours (with laminar augmentation)

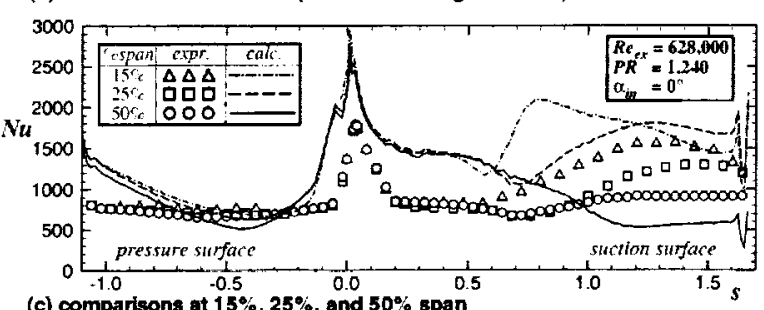

(c) comparisons at $15 \%, 25 \%$, and $50 \%$ span

Figure 9. Heat transfer distributions - Case 5

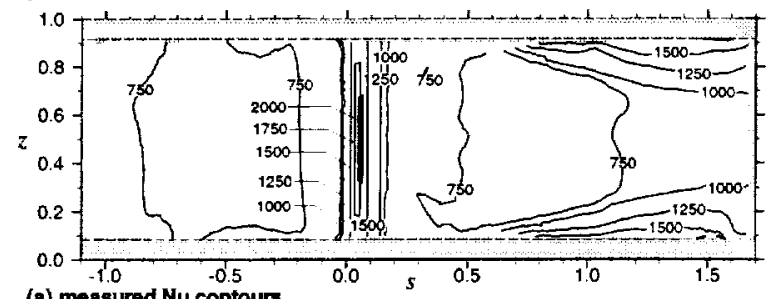

(a) measured Nu contours

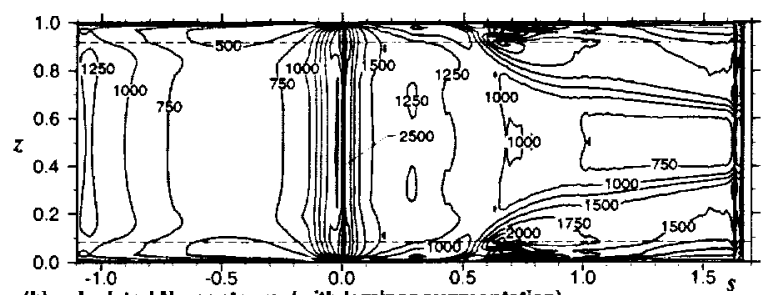

(b) calculated Nu contours (with laminar augmentation)

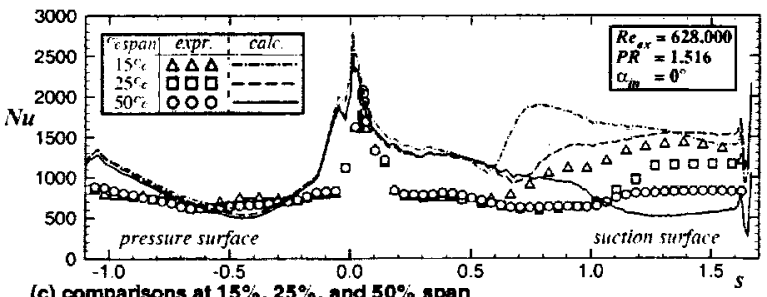

(c) comparisons at $15 \%, 25 \%$, and $50 \%$ span

Figure 10. Heat transfer distributions - Case 6

tion surface, a very slight increase in $N u$ is observed near $0.2 \leq s \leq 0.4$. This could indicate that transition started, but was damped by the accelerating flow. Farther back on the suction surface, the effects of the strong secondary flows are evident. Many of these effects can be attributed

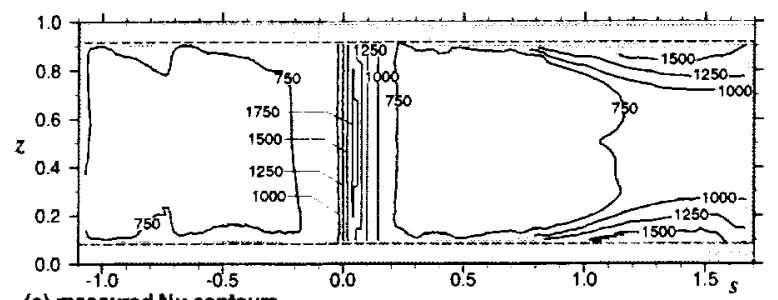

(a) measured Nu contours

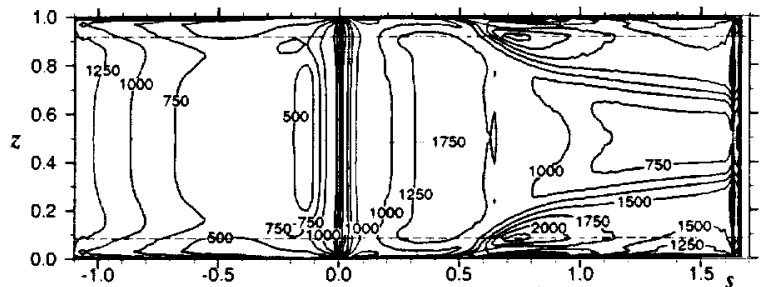

(b) calculated Nu contours (no laminar augmentation)

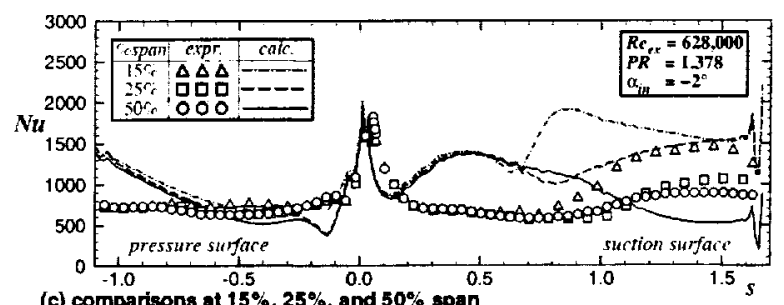

(c) comparisons at $15 \%, 25 \%$, and $50 \%$ span

Figure 11. Heat transfer distributions - Case 7

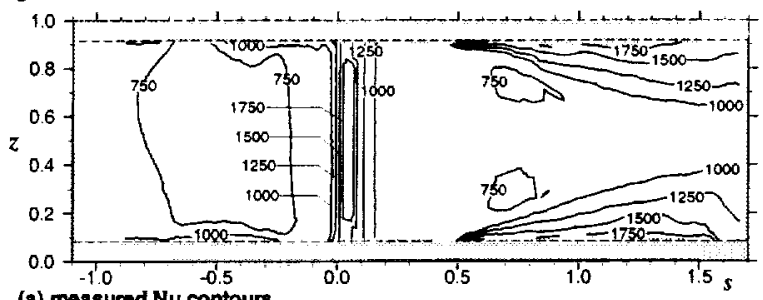

(a) measured Nu contours

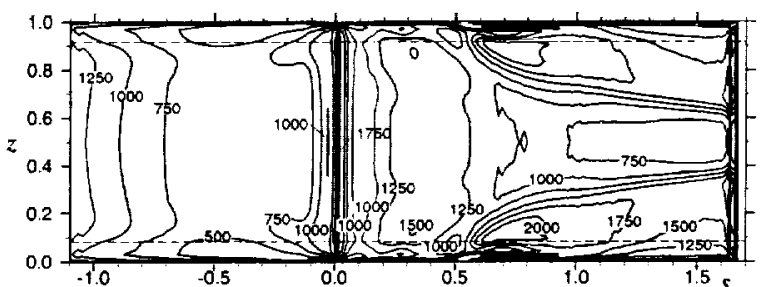

(b) calculated Nu contours (no laminar augmentation)

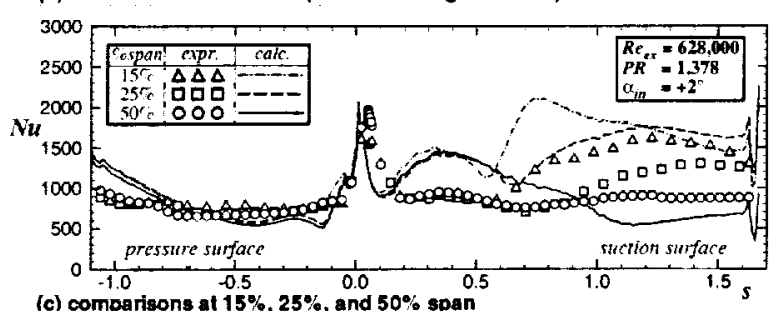

(c) comparisons at $15 \%, 25 \%$, and $50 \%$ span

Figure 12. Heat transfer distributions - Case 8

to the vortex structures described by Langston (1977). The passage vortex and the pressure-side leg of the horseshoe vortex approach the suction surface. Heat transfer is enhanced by the relatively cool secondary flow fluid impinging on the endwall regions of the suction surface. The vortices 
Table 2. Effects of Reynolds No. on Pressure Surface Heat Transfer

\begin{tabular}{|c|c|c|c|c|c|c|c|}
\hline \multirow[b]{2}{*}{ Case } & \multirow[b]{2}{*}{$R e_{e r}$} & \multirow[b]{2}{*}{$\Delta N u_{\text {lam }}$} & \multirow[b]{2}{*}{$\Delta N u_{t u r b}$} & \multicolumn{2}{|c|}{$s=-0.26$} & \multicolumn{2}{|c|}{$s=-0.51$} \\
\hline & & & & $N u$ & $\Delta V u$ & $N u$ & $\Delta N u$ \\
\hline 1 & 628.000 & & - & 712 & & 675 & - \\
\hline 2 & $-20 \%$ & $-11 \%$ & $-16 \%$ & 603 & $-15 \%$ & 607 & $-10 \%$ \\
\hline 3 & $+20 \%$ & $+10 \%$ & $+16 \%$ & 817 & $+15 \%$ & 751 & $+11 \%$ \\
\hline 4 & $+40 \%$ & $+18 \%$ & $+31 \%$ & 921 & $+29 \%$ & 816 & $+21 \%$ \\
\hline
\end{tabular}

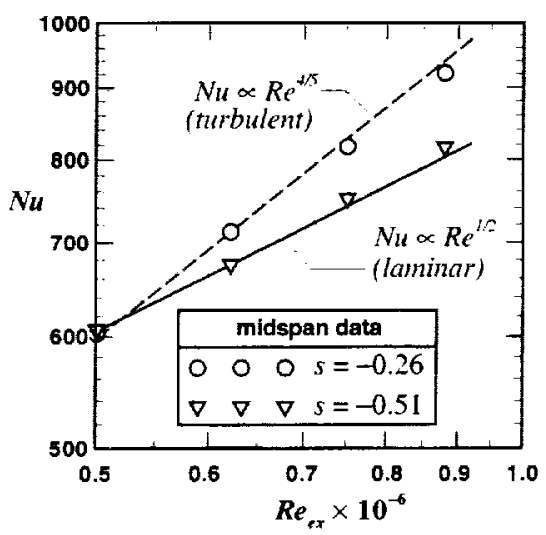

lift off the endwall and approach midspan, exiting the rotor at around $25 \%$ span. Their effect is seen in Fig. 5(c) as departures from midspan data; first at $15 \%$ span, $s=0.7$; then at $25 \%$ span, $s=1.1$. The data of Fig. 5(c) shows that midspan transition occurs over the approximate range $0.7 \leq s \leq 1.1$. Midspan $N u$ increases from 625 at $s=0.7$ to 824 at $s=1.4$. Note that this transition start occurs before the slight decelerating flow region. At $25 \%$ span, secondary flows enhance the heat transfer for $s>1.0$. This enhancement makes a determination of the end of transition difficult.

\section{Effects of Reynolds Number}

Table 2 lists and shows comparisons of Nusselt number data at two midspan points on the pressure surface. $\Delta N u_{\text {lam }}$ was determined by assuming $N u \propto R e_{e x}^{1 / 2}$ and $\Delta N u_{t u r b}$ was determined by assuming $N u \propto R e_{e x}^{4 / 5}$. Note from Fig. 4 that the flow at $s=-0.26$ is decelerating while the flow at $s=-0.51$ is strongly accelerating, but that the velocities at -0.51 are quite low.

Figure 6 shows results obtained at the design pressure ratio and inlet flow angle, but at a Reynolds number $20 \%$ less than design (Case 2). No transition start was observed near the end of the pressure surface as was seen for Case 1. The level region of $N u$ near $s=-0.1$ is still seen for this case. A comparison of heat transfer rates can be made at the midspan locations listed in Table 2. At $s=-0.26$ the change in $N u$ with $R e_{e x}$ is consistent with expected changes in a turbulent boundary layer. At $s=-0.51$, however, the change in $N u$ with $R e_{e x}$ is consistent with expected changes in a laminar boundary layer. This indicates that the flow transitioned in the decelerating flow region and then relaminarized under strong acceleration. The pressure gradient parameter of $K=12 \times 10^{-6}$ at $s=-0.51$ supports this. $K$ was greater than $3.5 \times 10^{-6}$ for $s<-0.42$.

The laminar stagnation point Frossling number of 0.870 from Van Fossen et al. (1995) is independent of Reynolds number. Equation (2) predicts an enhancement of 1.11 and thus a Frossling number of 0.968 . The measured value of 0.950 agrees much better than for Case 1 .

Heat transfer on the suction surface appears to be quite similar to that of Case 1, except that the lower Reynolds number has delayed transition all the way to the throat and to the decelerating flow region. No increase in $N u$ is observed near $0.2 \leq s \leq 0.4$ indicating that transition never started in that region. Fig. 6(c) shows the midspan transition region to be $1.00<s<1.35$. The fact that transition occurred in a decelerating flow region would account for the doubled relative $N u$ rise in going from the laminar value of 535 at $s=0.9$ to the fully turbulent value of 864 at $s=1.4$. Quarter-span transition appears to start at the same location but also to be more abrupt and intense. At $15 \%$ span, secondary flows apparently incited much earlier transition $(s \approx 0.6)$.

Figure 7 shows the effects of an increase in Reynolds number $20 \%$ over the design value. Pressure surface transition is quite evident for $s<-0.7$. Table 2 shows that the changes in $N u$ with $R e_{e x}$ are again consistent with turbulent flow at $s=-0.26$ and with relaminarized flow at $s=-0.51$. The measured peak $F r=0.866$ is $12 \%$ lower than the correlation prediction, similar to Case 1.

On the suction surface, definite increases in $\mathrm{Nu}$ are observed near $0.2 \leq s \leq 0.4$ at $15 \%, 25 \%$, and $50 \%$ span, indicating early transition despite the flow acceleration shown in Fig. 2. $N u$ levels gradually decrease after this, but then increase slightly to the throat at $s \approx 1.0$. At $s=0.7$, $N u=919$, an increase of $47 \%$ over the Case 1 value at the same location. This is a much greater increase than would be expected if the flow had remained laminar to this point, again indicating that the flow of Case 3 was transitional in this region. For $s>1.0$, midspan levels of $N u$ remain constant while quarter-span levels rise because of secondary flow effects. The $15 \%$ span results again show earlier transition and increased secondary flow heat transfer enhancement.

Case 4 results are presented in Fig. 8. This is the highest Reynolds number case, $40 \%$ over design. The trends noted in Case 3 are even more evident in this case. Pressure surface midspan transition starts at about the same location, $s=-0.7$. The flow appears to be fully turbulent near the end of the pressure surface. Table 2 again shows data consistent with turbulent flow at $s=-0.26$ and with 
relaminarized flow at $s=-0.51$. At $s=-1.0$, the midspan Nusselt number is 1365 as opposed to 1168 for Case 3 at the same location. This $17 \%$ increase is in good agreement with an expected increase of $13 \%$ assuming $N u \propto R e_{e x}^{4 / 5}$. This comparison could not be made for Cases 1 or 2 because the flow was either laminar or transitional at this location. The measured peak $F r=0.869$ is again $12 \%$ lower than the correlation prediction, but agrees well with the previous case. Transition is again evident near the beginning of the suction surface. The more pronounced decrease in $\mathrm{Nu}$ for $0.4 \leq s \leq 0.7$ may indicate that complete transition had occurred by $s \approx 0.4$. At a midspan distance of $s=0.7$, $N u$ increased from 919 for Case 3 to 1103 for Case 4. This $20 \%$ increase is slightly more than the $13 \%$ expected increase from Reynolds number. This may further indicate that the flow in Case 3 was still transitional at this point. After the throat, midspan levels of $N u$ continue to decrease as the fully turbulent boundary layer grows, while quarterspan levels increase because of secondary flow effects. The $15 \%$ span data is again significantly higher because of secondary flow heat transfer enhancement. In comparing the $15 \%$ span data from Cases $1-4$ it is observed that whether or not the flow transitioned early as was the case for the higher Reynolds number cases, the data at $15 \%$ span always departed from the $25 \%$ and $50 \%$ data and increased sharply at $s=0.7$. This gives an indication of the path of the horseshoe/passage secondary flow rortex.

\section{Effects of Pressure Ratio}

The isentropic exit pressure ratio was varied $\pm 10 \%$ from the design value of 1.378 . The independent inlet and exhaust control of the facility allowed the nominal exit Reynolds number to be held fixed at the design value of 620,000 for these cases. Changes in the inlet Reynolds number thus were minimal. Relative to the exit Reynolds number, $R e_{\text {in }}$ changed only $+2.3 \%$ for a $-10 \%$ change in $P R$ and changed $-3.3 \%$ for a $+10 \%$ change in $P R$.

The results for Case 5 are shown in Fig. 9. Comparing this to Case 1 in Fig. 5 shows the effects of an exit isentropic pressure ratio reduction of $10 \%$. On the pressure surface, those effects are minimal. Fig. 9(c) still shows a slight increase in $N u$ at the end of the pressure surface, indicating the start of transition. Table 1 shows that the peak Frossling number is 0.839 , again very close to that of the baseline case. Fig. 9(c) shows that the suction surface $N u$ distribution starts off the same and has the same qualitative trends, but ends up about $10 \%$ higher than the baseline case. No explanation for this can be found, except to note that because of day-to-day temperature variations, this case had the highest uncertainty, $12.4 \%$. It is interesting to note that Arts et al. (1998) also showed nearly identical pressure surface behavior and gradually increasing heat transfer differences along the suction surface with decreasing pressure ratio. They attributed this to shock/boundary layer interaction at their transonic Mach numbers, but it appeared to be evident even before the shock impingement location.

Figure 10 shows the results for a $10 \%$ increase in $P R$. Comparing the contour plot of Fig. 10(a) and the 15\%, 25\%, and $50 \%$ span line plots of Fig. 10(c) to those of the baseline case in Fig. 5 shows that the Nusselt number distributions are nearly identical. The only difference appears to be at the stagnation point where the Frossling number is $2 \%$ higher than the correlations would predict. This is in contrast to all of the other cases in which measured Frossling numbers were less that correlation predictions. No explanation can be offered for this.

\section{Effects of Incidence Angle}

Figure 11 shows the effects of -2 deg of incidence. The only appreciable difference from the baseline case appears to be on the pressure surface very near the stagnation region. Figure 5(c) showed a small, level region of $N u$ around $s=$ -0.1 . Figure 11(c) shows a slight dip in this same region that can be attributed to the negative incidence angle. This could indicate a small separation bubble or at least incipient separation. Arts et al. (1998) showed a similar, but much stronger effect of negative incidence for $a-5 \mathrm{deg}$ incidence case.

Figure 12 shows the effects of +2 deg of incidence. The pressure surface and stagnation region are very similar to the baseline case, but the suction surface shows signs of early transition. The effects are similar to a $20 \%$ increase in $R e_{e x}$ as shown in Fig. 7. Note, however, from Table 1 that the inlet Reynolds number for Case 8 is $11 \%$ higher than the baseline case even though the exit Reynolds numbers are nominally the same. The early transition leads to increased $N u$ levels on the remainder of the suction surface.

\section{COMPUTATIONAL HEAT TRANSFER RESULTS}

Figure 5(b) presents computed $N u$ contours while Fig. 5(c) presents comparisons with data at $15 \%, 25 \%$, and $50 \%$ span. For this and all subsequent figures, calculation results shown in part (c) correspond directly to those shown in part (b), either with or without the laminar augmentation model. The analysis for this case does not agree well with the experimental data. The analysis methods used for the comparisons had previously been verified by comparisons with experimental data. Giel et al. (1999) showed comparisons with experimental data using the same analysis, and the agreement was much better than for the results shown herein. The comparisons were for surface heat transfer on a 
rotor geometry tested in the same facility and with the same turbulence grid as the present data. While the test Mach numbers, Reynolds numbers, and the rotor geometry all differed from the current test, the blade row inlet conditions were similar. The blade of the current test has a significantly smaller leading edge diameter. The blade thickness just bchind the leading edge is also significantly less for the current blade which results in lower mid-passage velocities. These both influence the scale and intensity of turbulence within the blade row. Modeling for transition and the effect of turbulence on pre-transition heat transfer were verified by comparisons with rotor and stator data as shown by Boyle and Simon (1999). They compared midspan predictions with data and showed good agreement. The modeling approach of the two-dimensional analysis was incorporated into the three-dimensional analysis. The areas of disagreement between the predictions and the data herein illuminate areas where improved modeling is needed.

Figure 5 shows that the analysis significantly overpredicts the leading edge region heat transfer. The augmentation due to inlet turbulence is greater than measured. The model for augmenting leading edge heat transfer only accounts for turbulence intensity; it does not account for turbulence scale. As mentioned earlier, because of the large $\Lambda_{x} / d$ ratio, the expected leading edge augmentation was small. The leading edge Frossling number is close to 1.0 in the data, but the predicted value is nearly 1.5. The experimental data show transition beginning near $s=0.7$. Intermittency information from the CFD code indicates that the predicted suction surface transition start occurred at about $s=0.25$. Transition effects are not immediately evident in this region because the high heat transfer on the forward portion of the suction surface is due to augmenting the laminar viscosity to account for the effect of freestream turbulence. This is the same model as was used in the leading edge region. Consequently, the heat transfer is over-predicted. The differences in the augmentation model predictions between the current study and that of Giel et al. (1999) is attributed to their larger circular leading edge diameter-to-chord ratio and to their higher flow acceleration.

On the uncovered portion of the suction surface, $s>1$, the analysis under-predicts the midspan heat transfer, but over-predicts the heat transfer at $15 \%$ and $25 \%$ span. Between 30 and $40 \%$ of span in this region, the predicted heat transfer changes rapidly. The temperature and/or the amount of fluid being swept up the suction surface are not adequately predicted. In this region, while the local predictions are in error, the predicted spanwise average heat transfer at each $s$ location agrees reasonably well with the experimental spanwise average heat transfer. The analysis predicts the character of the heat transfer variation, but in the uncovered region, the variation is greater than the experimental variation. Additional calculations were performed with a heated endwall which showed, consistent with Giel et al. (1999), that the effect of the endwall thermal boundary condition on rotor heat transfer was relatively small, except very near the endwall. This indicates that the bulk of the secondary flow impacting the suction surface apparently came from the freestream.

The pressure surface heat transfer predictions have common characteristics for all cases. Transition occurred in the forward portion of the pressure surface. Figure 4 shows diffusion occurring between $s=-0.1$ and -0.4 . The diffusion resulted in the analysis predicting transition. $\mathrm{Nu}$ decreases despite transition because the velocity decreases. For most of the pressure surface the predicted flow was turbulent. The pressure surface heat transfer predictions shown in Figs. 512 agree well with the data when the Reynolds number was greater than design. The model did not account for relaminarization of a turbulent boundary layer. The pressure gradient parameter, $K^{-}$, was calculated. For the rear half of the pressure surface at the design Reynolds number and below, the $K$ value was greater than $3 \times 10^{-6}$ everywhere. At these two lower Reynolds numbers, the data did not indicate transition. Reference calculations were run for purely laminar flow at the design flow conditions. The results on the pressure surface indicate that a minimum Nusselt number of 250 was calculated at $s \approx-0.15$, similar to the calculated minimum shown in Fig. 6. The purely laminar predicted heat transfer then increased almost linearly to $N u=600$ at the pressure surface trailing edge. The experimental heat transfer is higher than was predicted for the purely laminar boundary layer. In effect it is a buffeted laminar boundary layer.

The predictions in Fig. 6 show the consequences of neglecting the effect of turbulence augmentation in the laminar region. While the heat transfer in the leading edge region is now well predicted, previous comparisons (Giel et al., 1999) needed augmentation in this region to agree well with the data. Without the augmentation, the increase in predicted heat transfer caused by transition near $s=0.7$ is more clearly seen at $25 \%$ and $50 \%$ span. Excellent agreement with data is seen at $15 \%$ span for $s>0.5$. With the laminar augmentation model turned on, intermittency information from the CFD code indicated a transition start location of $s=0.2$. In the transition start model, an $18 \%$ decrease in Reynolds number is equivalent to a $26 \%$ decrease in inlet turbulence intensity. Prior to transition, the suction surface heat transfer is now lower than the data. The predicted spanwise heat transfer variation in Fig. 6 is similar to that shown in Fig. 5 . On the uncovered part of the suction surface the flow is turbulent, and the same modeling is used. 
The comparisons shown in Fig. 7 at the higher Reynolds number show better agreement with the data for the rear portion of the pressure surface than did the comparison shown in Fig. 5 at the design Reynolds number. The overprediction due to the augmentation model is the same for both figures. Again, the predicted midspan heat transfer on the uncovered portion of the suction surface is lower than the data, and the $15 \%$ and $25 \%$ predictions are higher than measured. The spanwise average predicted heat transfer is higher than measured. The experimental data in Fig. 7 show an increase at $s \approx 0.3$ that is consistent with earlier suction surface transition. The data of Fig. 5 indicates that for the design Reynolds number transition occurred much later, at $s \approx 0.7$. For Case 3 , intermittency information from the CFD code indicated that the predicted suction surface transition start occurred at about $s=0.2$, approximately where early transition effects are evident in the experimental data.

Even though it is not shown in Fig. 8, the pre-transition heat transfer with augmentation over-predicted the data by the same ratio as shown in Figs. 5 and 7. The increase in Reynolds number did not affect the relative agreement. Figure 8 shows that without the augmentation, the agreement is good in the leading edge region. At this high Reynolds number the pressure surface heat transfer is well predicted. The predicted suction surface transition is much closer to the leading edge than is seen in the data. Transition was predicted to begin in a favorable pressure gradient region. In favorable pressure gradients the location of the start of transition is very sensitive to the inlet turbulence level. The momentum thickness Reynolds number grows slowly with distance, and the freestream turbulence decreases with accelerating flows. While the data gives evidence of transition beginning at $s$ near 0.2 , the heat transfer increase is much less than the predicted increase.

Comparing the predictions in Figs. 9 and 10 with those in Fig. 5 show almost identical results. Even though the pressure ratio changed, the exit isentropic Reynolds number did not. The inlet Reynolds number changed only slightly. Consequently, there was no mechanism to alter the predictions. The data are almost identical, and the ratio of predicted to measured heat is the same as in Fig. 5.

The predictions in Figs. 11 and 12 are with no augmentation for the laminar region. The leading edge heat transfer is well predicted. The midspan data show that, even though the inlet Reynolds number was only $11 \%$ greater for the positive incidence case in Fig. 12, the start of suction surface transition moved significantly closer to the leading edge. Comparing midspan measurements in Figs. 11 and 12 show a small, but noticeable, heat transfer difference just downstream of the leading edge on the pressure surface. The variation is due to the different incidence angles. The predictions show a similar variation in the minimum values near $s=-0.13$.

\section{SUMMARY AND CONCLUSIONS}

Detailed aerodynamic and heat transfer measurements and predictions were given for a power generation turbine rotor under engine specific conditions. The effects of variations in Reynolds number, exit pressure ratio, and incidence angle were quantified. The primary effect of Reynolds number variations in the range of $-20 \%$ to $+40 \%$ was to move the locations of laminar-to-turbulent transition. Variations in isentropic exit pressure ratio over a range of $-10 \%$ to $+10 \%$ were found to have little effect on the blade heat transfer. Positive incidence of $2 \mathrm{deg}$ had almost no effect on blade heat transfer while 2 deg of negative incidence resulted in what could have been the start of a small pressure surface separation bubble just downstream of the stagnation region. In the fully laminar or fully turbulent flow regions, the data agreed well with the appropriate scaling laws.

The good spatial resolution due to the large scale and the liquid crystal measurement technique allowed the secondary flow effects to be clearly quantified. These secondary flows significantly increased suction surface heat transfer rates near the endwalls. The data also quantified the threedimensional impact of laminar-to-turbulent transition on blade heat transfer. Excellent midspan symmetry was observed for all cases.

Comparing computational and experimental results illustrated regions of good agreement and regions where modeling improvements are needed. This data set showed, for example, that improvements to the laminar augmentation model are needed, even though this model worked successfully for previous studies from the same facility. 


\section{REFERENCES}

Arnone, A, Liou, M.-S, and Povinelli, L. A., 1992, "Navier-Stokes Solution of Transonic Cascade Flows Using Non-Periodic C-Type Grids," AIAA Journal of Propulsion and Power, Vol. 8, No. 2, pp. 410-417.

Arts, T., Duboue, J.-M., and Rollin, G., 1998, "Aerothermal Performance Measurements and Analysis of a Two-Dimensional High Turning Rotor Blade," ASME Journal of Turbomachinery, Vol. 120, No. 3, pp. 494-499.

Baines, W. D., and Peterson, L. G., 1951, "An Investigation of Flow Through Screens," Trans. ASME, Vol. 73, pp. 467480.

Baughn, J. W., Butler, R. J., Byerlcy, A. R., and Rivir, R. B., 1995, "An Experimental Investigation of Heat Transfer, Transition and Separation on Turbine Blades at Low Reynolds Number and High Turbulence Intensity," ASME paper 95-WA/HT-25.

Blair, M. F., 1994, "An Experimental Study of Heat Transfer in a Large-Scale Turbine Rotor Passage," ASME Journal of Turbomachinery, Vol. 116, No. 1, pp. 1-13.

Boyle, R. J., and Simon, F. F., 1999, "Mach Number Effects on Turbine Blade Transition Length Prediction," AS.ME Journal of Turbomachinery, Vol. 121, No. 4. pp. 694702 .

Camci, C. and Arts, T., 1991, "Effect of Incidence on Wall Heating Rates and Aerodynamics on a Film Cooled Transonic Turbine Blade," ASME Journal of Turbomachinery, Vol. 113, No. 3, pp. 493-513.

Chima, R. V., and Yokota, J. W., 1990, "Numerical Analysis of Three-Dimensional Viscous Internal Flows," AIAA Journal, Vol. 28, No. 5, pp. 798-806.

Chima, R. V., 1991, "Viscous Three-Dimensional Calculations of Transonic Fan Performance," AGARD Propulsion and Energetics Symposium on Computational Fluid Mechanics for Propulsion, San Antonio, Texas, May 27-31.

Chima, R. V., Giel, P. W., and Boyle, R. J., 1993, "An Algebraic Turbulence Model for Three-Dimensional Viscous Flows," AIAA paper 93-0083. (NASA TM-105931).

Dunn, M. G., Kim, J., Civinskas, K. C., and Boyle, R. J., 1994, "Time-Averaged Heat Transfer and Pressure Measurements and Comparison with Predictions for a Two-Stage Turbine," ASME Journal of Turbomachinery, Vol. 116, pp. 14-23.

Giel, P. W., Thurman, D. R., Lopez, I., Boyle, R. J., Van Fossen, G. J., Jett, T. J., Camperchioli, W. P., and La, H., 1996, "Three-Dimensional Flow Field Measurements in a Transonic Turbine Cascade," ASME paper 96-GT-113, presented at the ASME International Gas Turbine Conference, Birmingham, England, June $10-13$.

Giel, P. W., Thurman, D. R., Vau Fossen, G. J., Hippensteele, S. A., and Boyle, R. J., 1998, "Endwall Heat Transfer Measurements in a Transonic Turbine Cascade,"
ASME Journal of Turbomachinery, Vol. 120, No. 2, pp. 305 313.

Giel, P. W., Van Fossen, G. J., Boyle, R. J., Thurman, D. R., and Civinskas, K. C., 1999, "Blade Heat Transfer Measurements and Predictions in a Transonic Turbine Cascade," ASME paper 99-GT-125, presented at the ASME International Gas Turbine Conference, Indianapolis, IN, June $7-10$.

Graziani, R. A., Blair, M. F., Taylor, R. J., and Mayle, R. E., 1980, "An Experimental Study of Endwall and Airfoil Surface Heat Transfer in a Large Scale Turbine Blade Cascarle," ASME Journal of Engineering for Power, Vol. 102, No. 2, pp. 1-11.

Guenette, G. R., Epstein, A. H., Giles, M. B., Haimes, R., and Norton, R. J. G., 1989, "Fully Scaled Transonic Turbine Rotor Heat Transfer Measurements," ASME Journal of Turbomachinery. Vol. 111, No. 1. pp. 1-7.

Joslyn, D., and Dring, R., 1992, "Three-Dimensional Flow in an Axial Turbine: Part 1 -... Aerodynamic Mechanisms," ASME Journal of Turbomachinery, Vol. 114, No. 1, pp. 61.70 .

Kays, W. M., and Crawford, M. E., 1980, Convective Heat and Mass Transfer, 2nd. Ed, McGraw-Hill, New York.

Kline, S. J., and McClintock, F. A., 1953, "Describing Uncertainty in Single-Sample Experiments," Mechanical Engineering, Vol. 75, Jan., pp. 3-8.

Langston, L. S., 1980, "Crossflows in a Turbine Cascade Passage," ASME Journal of Engineering for Power, Vol. 102 , pp. $866-874$.

Mayle, R.E., 1991, "The Role of Laminar-Turbulent Transition in Gas Turbine Engines," ASME Journal of Turbomachinery, Vol. 113, pp. 509-537.

Moffat, R. J., 1990, "Experimental Heat Transfer," Proc. of the Ninth Int'l Heat Transfer Conf., Jerusalem, Israel, Vol. 1, pp. 187-205.

Schlichting, H., 1979, Boundary-Layer Theory, Seventh Edition, McGraw-Hill, New York, p. 714.

Smith, M. C. and Kuethe, A. M., 1966, "Effects of Turbulence on Laminar Skin Friction and Heat Transfer," The Physics of Fluids, Vol. 9, No. 12, pp. 2337-2344.

Solomon, W. J., Walker, G. J., and Gostelow, J. P., 1995, "Transition Length Prediction For Flows With Rapidly Changing Pressure Gradients," ASME paper 95GT-241.

Thulin, R. D., Howe, D. C., and Singer, I. D., 1982, "Energy Efficient Engine - High-Pressure Turbine Detailed Design Report," NASA CR-165608.

Van Fossen, G. J., Simoneau, R. J., and Ching, C. Y., 1995, "Influence of Turbulence Parameters, Reynolds Number, and Body Shape on Stagnation-Region Heat Transfer," ASME Journal of Heat Transfer, Vol. 117, pp. 597-603, also NASA TP 3487, 1994. 


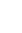

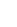



Davis Highway. Sutte 1204, Arlington, VA 22202-4302, and to the Office of Management and Budget. Paperwork Reduction Project (0704-0188), Washington, DC 20503.

\begin{tabular}{l|l|l|}
\hline 1. AGENCY USE ONLY (Leave blank) & 2. REPORT DATE & 3. REPORT TYPE AND DATES COVERED
\end{tabular}

\begin{tabular}{|l|c|c|}
\hline 1. AGENCY USE ONLY (Leave blank) & $\begin{array}{c}\text { 2. REPORT DATE } \\
\text { April } 2000\end{array}$ & $\begin{array}{r}\text { 3. REPORT TYPE AND DATES COVERED } \\
\text { Technical Memorandum }\end{array}$ \\
\hline
\end{tabular}

\section{TITLE AND SUBTITLE}

Heat Transfer Measurements and Predictions on a Power Generation

Gas Turbine Blade

6. AUTHOR(S)
5. FUNDING NUMBERS

WU-523-26-13-00

Paul W. Giel, Ronald S. Bunker, G. James Van Fossen, and Robert J. Boyle

\section{PERFORMING ORGANIZATION NAME(S) AND ADDRESS(ES}

National Aeronautics and Space Administration

John H. Glenn Research Center at Lewis Field

Cleveland, Ohio 44135-3191

\section{SPONSORING/MONITORING AGENCY NAME(S) AND ADDRESS(ES)}

National Aeronautics and Space Administration

Washington, DC 20546-0001
8. PERFORMING ORGANIZATION REPORT NUMBER

E-12218

10. SPONSORING/MONITORING AGENCY REPORT NUMBER

NASA TM-2000-210021

ASME 2000-GT-0209

11. SUPPLEMENTARY NOTES

Prepared for the 45th International Gas Turbine and Aeroengine Technical Congress cosponsored by the American Society of Mechanical Engineers and the International Gas Turbine Institute, Munich, Germany, May 8-11, 2000. Paul W. Giel, Dynacs Engineering Company, Inc., Brook Park, Ohio 44142 (work funded by NASA Contract NAS3-98008); Ronald S. Bunker, Corporate Research and Development, General Electric Corporation, Schenectady, New York 12301; G. James Van Fossen and Robert J. Boyle, NASA Glenn Research Center. Responsible person, Robert J. Boyle, organization code 5820, (216) 433-5889.

12a. DISTRIBUTION/AVAILABBILITY STATEMENT

12b. DISTRIBUTION CODE

Unclassified - Unlimited

Subject Categories: 02,07 and 34

Distribution: Nonstandard

This publication is available from the NASA Center for AeroSpace Information, (301) 621-0390.

13. ABSTRACT (Maximum 200 words)

Detailed heat transfer measurements and predictions are given for a power generation turbine rotor with 129 deg of nominal turning and an axial chord of $137 \mathrm{~mm}$. Data were obtained for a set of four exit Reynolds numbers comprised of the design point of $628,000,-20 \%,+20 \%$, and $+40 \%$. Three ideal exit pressure ratios were examined including the design point of $1.378,-10 \%$, and $+10 \%$. Inlet incidence angles of $0 \mathrm{deg}$ and $+2 \mathrm{deg}$ were also examined. Measurements were made in a linear cascade with highly three-dimensional blade passage flows that resulted from the high flow turning and thick inlet boundary layers. Inlet turbulence was generated with a blown square bar grid. The purpose of the work is the extension of three-dimensional predictive modeling capability for airfoil external heat transfer to engine specific conditions including blade shape, Reynolds numbers, and Mach numbers. Data were obtained by a steady-state technique using a thin-foil heater wrapped around a low thermal conductivity blade. Surface temperatures were measured using calibrated liquid crystals. The results show the effects of strong secondary vortical flows, laminar-to-turbulent transition, and also show good detail in the stagnation region.

\section{SUBJECT TERMS}

Gas turbines; Heat transfer; Transonic flow; Cascade wind tunnel; Turbomachinery; Liquid crystals

17. SECURITY CLASSIFICATION
OF REPORT
Unclassified

8. SECURITY CLASSIFICATION
OF THIS PAGE
Unclassified
19. SECURITY CLASSIFICATION OF ABSTRACT Unclassified

15. NUMBER OF PAGES 16. PRICE CODE

$$
\mathrm{AO} 3
$$

20. LIMITATION OF ABSTRACT 